\title{
Application of Geostatistical Inversion Data in Thin Sand Body Modeling
}

\author{
Qiang Wang \\ Northeast Petroleum University, Daqing 163318,China \\ hljsakura@163.com
}

Keywords: Geostatistics; Seismic Inversion; Geological Modeling; Wave Impedance

\begin{abstract}
On the basis of understanding the reservoir characteristics of Block $\mathrm{S}$, this paper established the sand body and oil reservoir property model with geostatistical inversion data, in combination with geological modeling technology and petrel software under the restriction of sandstone vertical probability and wave impedance. The result showed under the control of sedimentation model, the combination of geostatistical seismic inversion and geological modeling technology could comprehend the advantages of shaft data and seismic data information and improve the prediction accuracy of inter-shaft and vertical reservoir. This method has a guiding significance in the evaluation of thin-layer oil reservoir and the shaft site deployment.Reservoir modeling and seismic data inversion are two technologies to predict the transverse spreading characteristics of the reservoir [1], and the two have different emphases. The geological modeling is used to quantitatively characterize and depict the non-homogeneity characteristics of reservoir, predict the uncertainty and risk in oil and gas survey and development. The advantage of seismic inversion technology lies in the extensive transverse coverage of seismic data. However, due to the limitation of seismic resolution, it is difficult to predict the thin reservoir. In recent years, the geostatistical inversion has played a more and more important role in the reservoir prediction [2-5]. For the thin oil reservoir, only by combining the two technologies can the reservoir be described accurately.
\end{abstract}

\section{Geological overview}

Block $S$ is located in the south of Jiangqiao region. The main oil reservoirs are GI oil reservoir and SII+III oil reservoir. In the process of evaluation, Block S exposes the phenomenon of quick change of reservoir and it is difficult to track. In the seismic profile, the river channel sand body has a poor reflection connection and it is difficult to predict the reservoir. In recent years, the horizontal shaft technology in Jiangqiao region has been applied more and more widely, and higher requirements have been proposed for the accuracy of sand body prediction. Therefore, it is required to improve the reservoir prediction accuracy through well shock on the basis of understanding the reservoir characteristics, so as to provide a scientific basis for the establishment of development plan and the deployment of well site.

\section{Stratigraphic Cycle Comparison}

In Block S, GI and SII+III oil reservoirs are dominated by the front edge of delta. In the period of SI and S0, it was shallow lake subfacies sedimentation. The cycle comparison was applied to 
divide the stratum of GI and SII+III oil reservoirs, with stable mark stratum of S0, SI sand layer top limnetic facies dark grey mudstone section, with stable sedimentation and the whole area could be compared and tracked continuously. The top and floor of SII+III sand layer were selected as the auxiliary standard layer. According to the lithologic characteristics and curve cycle, the 4 sand layers were further divided into 14 sub-layers.

\section{Reservoir Development Characteristics}

The main types of Block S sand body include underwater distributary channel, estuary dam, sand bank and sheet band, with porosity $32.8 \%$ on average and permeability $1033 \times 10-3 \mu \mathrm{m} 2$ on average, belonging to the high-porosity and medium and high-permeability reservoir.

According to the statistics (Table.1), the thickness of sand body in SII+III oil reservoir is large, with single layer thickness 3-7.4m; in SI group, sandstone developed in SI2, with thickness 3.76m; the thickness of sand body in S0 group is the minimum, $0.15-4.9 \mathrm{~m}$ on average. The sandstone drilling ratios in each group vary a lot. The drilling rate of sand in SII+ III group is $46.15 \%-64.1 \%$, and that in S0 group is $12.82 \%$. Overall, Block S has a small thickness of sand body, thin reservoir.

Table 1 Statistical Form of Sand Body Development Condition of Oil Reservoir in Block S

\begin{tabular}{c|c|c|c|c|c}
\hline & $\begin{array}{c}\text { Minimum } \\
\text { sandstone } \\
\text { thickness } \\
(\mathrm{m})\end{array}$ & $\begin{array}{c}\text { Maximum sandstone } \\
\text { thickness (m) }\end{array}$ & $\begin{array}{c}\text { Average sandstone } \\
\text { thickness (m) }\end{array}$ & $\begin{array}{c}\text { Drilling rate } \\
(\%)\end{array}$ & Sand-stratum ratio \\
\hline S0 & $0.6 \sim 1$ & $1.2 \sim 9.1$ & $0.15 \sim 4.9$ & $12.82 \sim 56.41$ & $0.01 \sim 0.19$ \\
\hline SI & 1 & 7.22 & 3.76 & 53.85 & 0.21 \\
\hline SII+III & $0.6 \sim 2.6$ & $3.12 \sim 8.5$ & $3.01 \sim 7.4$ & $46.15 \sim 64.10$ & $0.14 \sim 0.38$ \\
\hline GI & $1.1 \sim 1.3$ & $15.64 \sim 19.5$ & $5.47 \sim 6.79$ & $64.10 \sim 69.23$ & $0.28 \sim 0.33$ \\
\hline
\end{tabular}

\section{Geostatistical inversion}

The geostatisticl inversion can reflect the physical nature and spatial structure of the underground rock stratum. According to the geological and well logging data, seismic data and a certain mathematical algorithm, it obtains a wider and wider application in the stratum. The StatMod MC geostatistical inversion technology of Jason software is applied for reservoir inversion and beneficial reservoir prediction.

The compliance rate of inversion result of geostatistics is $77 \%$. The absolute error of pair well of 3D site SII+III1, 2 sub-layer sandstone forecast is between -9.26 and $0.24 \mathrm{~m}$, the relative error is between $-3.75 \%$ and $3.13 \%$, and the relative error of pair well error of sandstone forecast is less than $20.0 \%$, which conforms to the precision requirements, and can meet the demand for the reservoir forecast (Table 2).

Table 2 Statistical Form of Pair Well Error of SII+III $I_{1,2}$ Layer Sandstone Forecast in Block S

\begin{tabular}{c|c|c|c|c|c}
\hline $\begin{array}{c}\text { Sandstone } \\
\text { thickness (m) }\end{array}$ & $\begin{array}{c}\text { Number of } \\
\text { wells }\end{array}$ & $\begin{array}{c}\text { Statistical value of } \\
\text { sandstone thickness (m) }\end{array}$ & $\begin{array}{c}\text { Forecasted value of } \\
\text { sandstone thickness } \\
(\mathrm{m})\end{array}$ & Absolute error (m) & Relative error (\%) \\
\hline$<2$ & 3 & $0 \sim 1.23$ & $0 \sim 1.26$ & $0 \sim-0.03$ & $0 \sim-3.45$ \\
\hline$\leqslant 4<6$ & 6 & $4 \sim 5$ & $4.06 \sim 5.16$ & $-0.16 \sim 0.09$ & $-3.75 \sim 2.05$ \\
\hline
\end{tabular}




\begin{tabular}{c|c|c|c|c|c}
\hline$\leqslant 6<8$ & 4 & $6.4 \sim 7.6$ & $6.2 \sim 7.81$ & $-0.21 \sim 0.2$ & $-2.76 \sim 3.13$ \\
\hline$\leqslant 8<10$ & 8 & $9.12 \sim 9.8$ & $9 \sim 9.74$ & $-0.26 \sim 0.15$ & $-2.83 \sim 1.56$ \\
\hline$\geqslant 10$ & 4 & $10.18 \sim 11.8$ & $10.02 \sim 11.56$ & $0.09 \sim 0.24$ & $0.85 \sim 2.03$ \\
\hline
\end{tabular}

\section{Geological Modeling}

Structural model. The structural model includes fault model and layer model, which describes the development characteristics of the fault system and the change of stratum thickness distribution under the structural background, and the contact relation between the vertical stratums [10].

Fault model. According to the range of the work site, the large and small faults explained to have control role and non-control role to oil, gas and entrapment were to select to establish the fault model. There are totally 29 faults in the block, in which No. JQ5 fault is the main controlling-reservoir fault, running through the north and south of the work site. There are three developed faults concentrated in the bock: the fault near the northeastern depression is dominated by the north-east

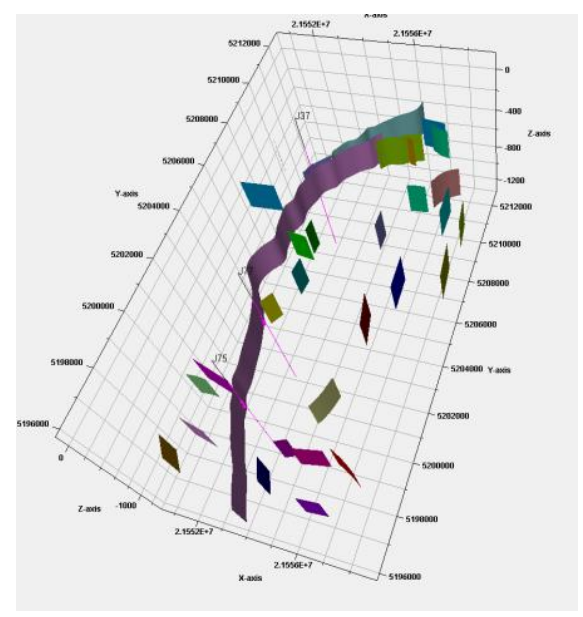

Fig. 1 Fault model direction, the central fault is of north-south direction and the southern fault is dominated by the near west-east direction (Fig. 1).

Stratum grid model. According to the stratum division and geological structure explanation result, well shock combination was applied to establish the structural model of GI and Saertu oil reservoir. According to the cycle comparison of the divided sub-layer, with the seismic explanation of oil reservoir top and boom structural form as the restriction condition, including Neijing section 1 top (T07), Yaojia group top (T1) and Gaotaizi top (T1-1), it was defined as the explanatory level of structural modeling.

Lithofacies model. On the basis of precise calibration of well seismic level, the wave impedance inversion was transferred to the depth field according to the speed model, and through the analysis and comparison of the well data, according to the wave impedance profile obtained in geostatistical inversion method, as the research area has a high content of mud, the relation between wave impedance and sand stone was not obvious, which was inconsistent with actual condition (Fig. 2). And it is needed to use the geological modeling technology to increase the reservoir modeling.

The oil reservoir in Block $\mathrm{S}$ is controlled by the structural and lithology factors. According to the reservoir development characteristics, the main reservoir SII+III group underwater distributary channel sand body is of strip distribution with high content of mud. Furthermore, the research area is in the evaluation stage, with small density of well network and large space between wells. To accurately forecast the distribution of

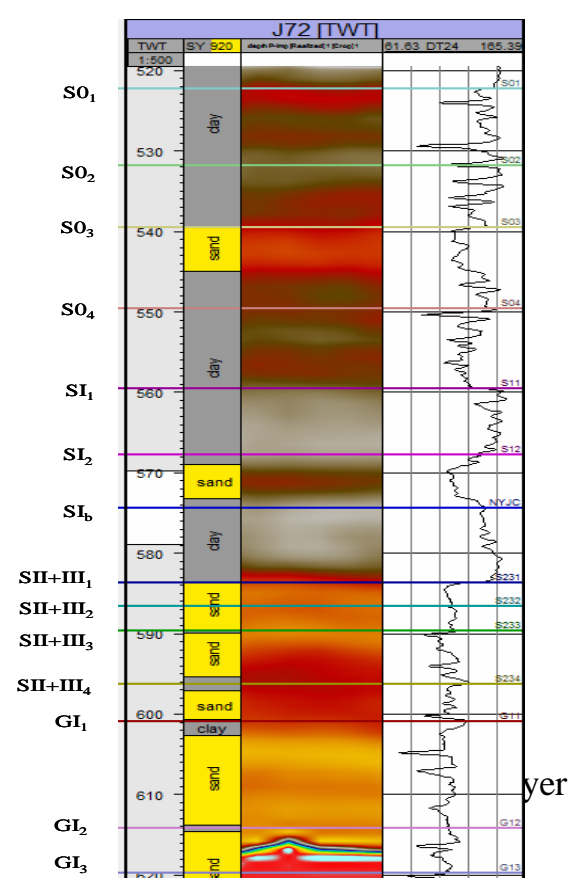


sand body, under the restriction of sedimentation model, it is a good research thought to combine the geostatistical inversion and geological modeling.

Variation function analysis. According to the analysis and statistical result of earthquake and well data, the variation function was preferred and established, and the parameters to be determined included primary range, secondary range, vertical range and direction etc. According to the earthquake wave impedance data, the plane variation function was analyzed, the sedimentation direction in the research area was an approximate north-south direction. In the plane, the range of $90^{\circ}$ in main direction is $3000 \mathrm{~m}$, and the range in $0^{\circ}$ of the secondary direction was $1000 \mathrm{~m}$, the analys is result was consistent with the understanding of regional geology. The well data were used to analyze the vertical variance function to get the longitudinal range about $5 \mathrm{~m}$, which reflected the thickness characteristics of the thin sand body.

Lithofacies modeling. The logging explanatory lithofacies data were discretized to analyze the probability of the wave impedance body and sandstone layer by layer (Fig. 3); according to the probability statistical relation (Fig. 4) and the variation function analysis result, under the restriction of sedimentary microfacies map (Fig. 5), the sequential indicator simulator model was used to crate the high-resolution thin lithofacies model under the restriction of wave impedance body (Fig. 6). According to the sand body prediction result, under the sand body boundary restriction predicted with sedimentary model the seismic data controlled the continuity of inter-well sand body. At the same time, through the comparison with the wave impedance profile, the sand body model effectively increased the vertical resolution of the reservoir prediction result (Fig. 7 and 8).
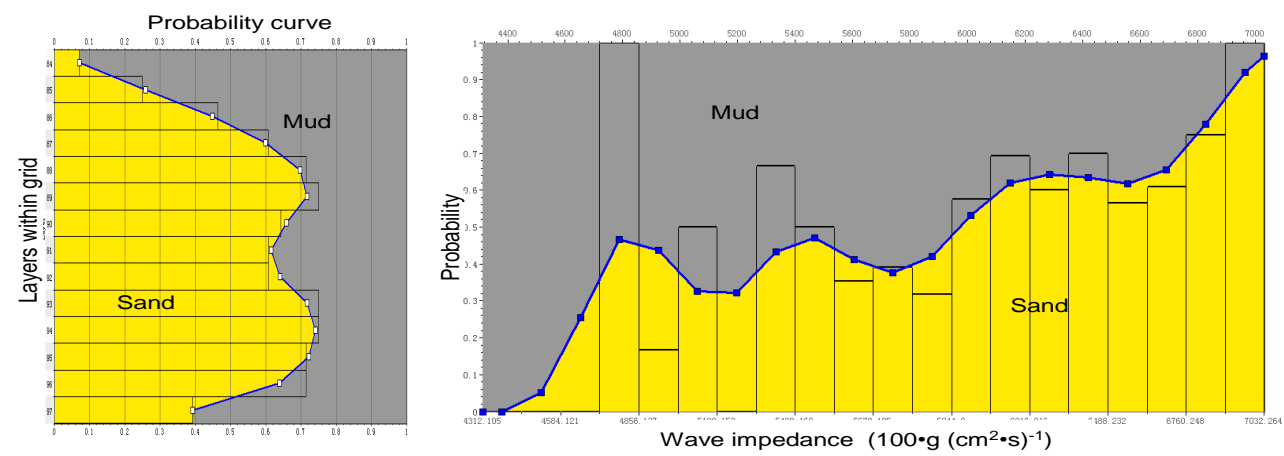

Fig. 3 Vertical probability of $\mathrm{SII}+\mathrm{III}_{2}$ layer sand stone

Fig. 4 Relation between sandstone and wave impedance in $\mathrm{SII}+\mathrm{III}_{2}$ layer

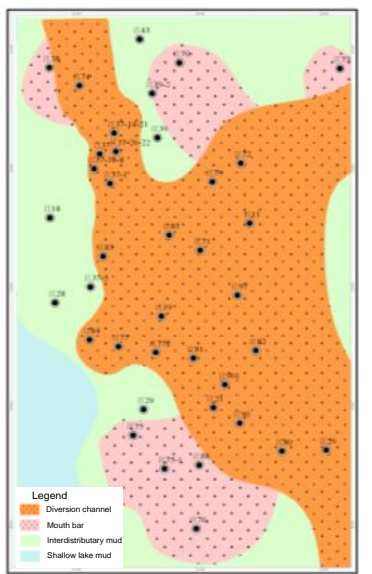

Fig. 5 SII+III ${ }_{2}$ sedimentary microfacies map

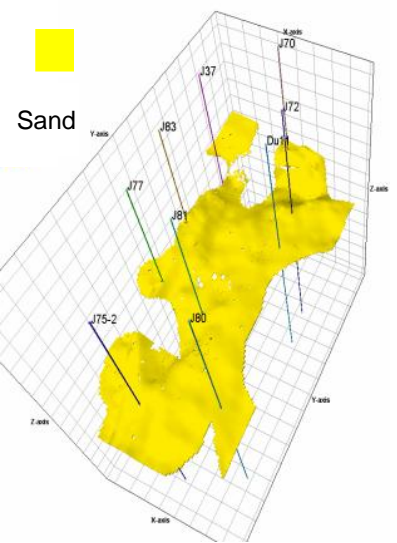

Fig. $6 \mathrm{SII}+\mathrm{III}_{2}$ sand body model 


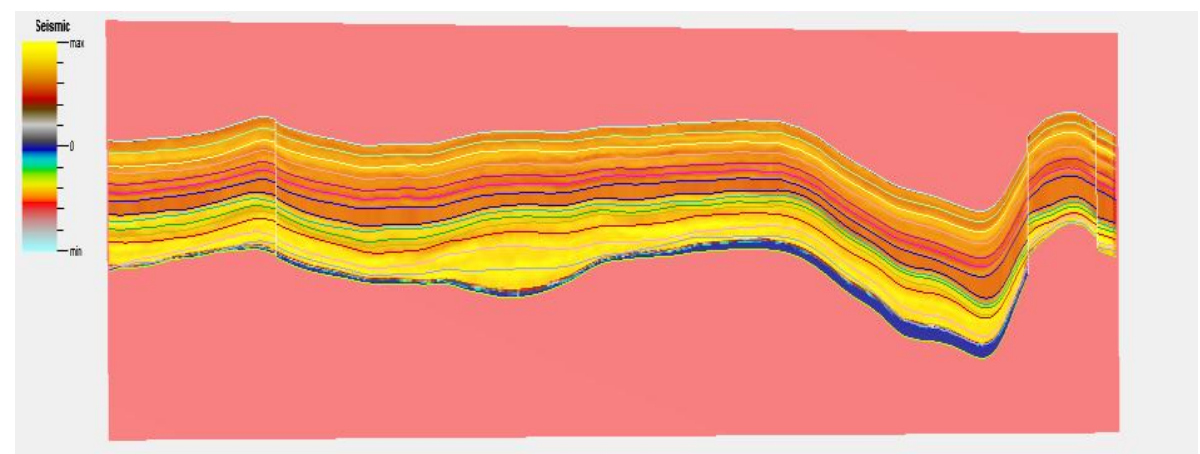

Fig. 7 Profile of wave impedance model

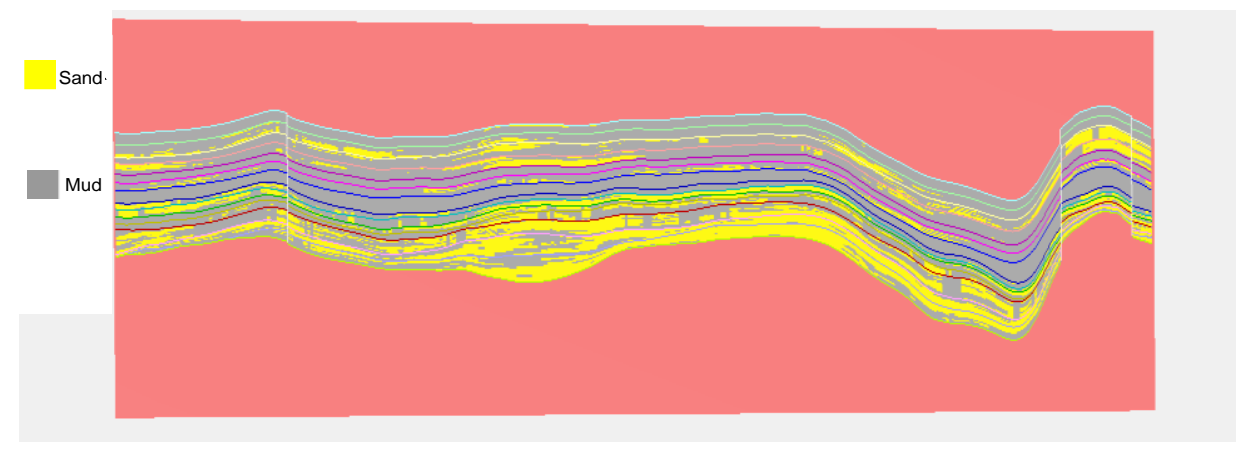

Fig. 8 Profile of sand body model

Oil reservoir property model. The 3D property modeling adopted the SGS analogue algorithm under the phase control condition, and on the basis of lithology model, the parameter statistical characteristics and variation function obtained with data analysis were used to respectively simulate the porosity, permeability and oil-bearing saturation property model and describe the spatial change characteristics of reservoir physical property (Fig. 9 and 10)

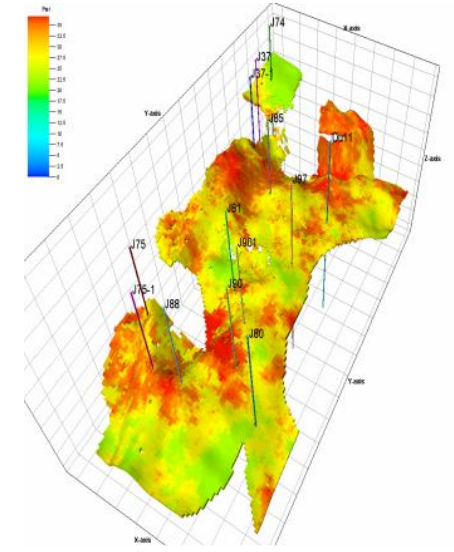

Fig. 9 SII+III 2 Porosity Model

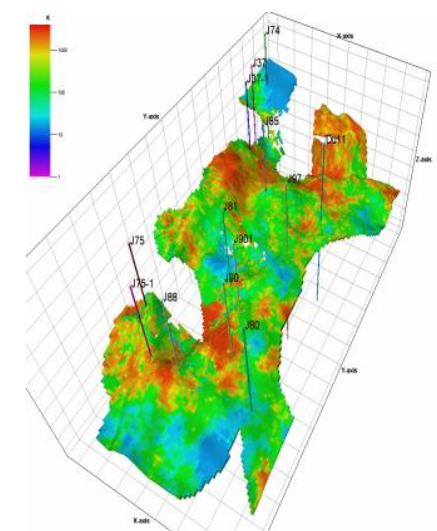

Fig. $10 \quad$ SII $+\mathrm{III}_{2}$ Permeability Model

\section{Conclusions}

(1) SII+III layer of Block $\mathrm{S}$ is the frontal facies sedimentation of delta, and the reservoir sedimentation types mainly include underwater distributary channel sand and estuary dam sand. Due 
to high content of mud and thin thickness of single layer, it is difficult to accurately predict the sand body just by relying on the geological data.

(2) The combination of geostatistical inversion and geological modeling technology has a good effect to predict the thin sand body, which guarantees the high consistency of the prediction result with the well while maintaining the reservoir plane distribution characteristics of the inversion result.

\section{References}

[1] Liu Wenling, Geological Modeling Technology of Seismic Restriction Reservoir [J], Petroleum Journal, 2008, 29(1): 64-68.

[2] Wang Xiangwen, Liu Hong, Teng Binbin et al., Application of Geostatistical Inversion Technology in Prediction of Thin Reservoir [J], Petroleum and Natural Gas Geology, 012, 33(5): 730-736.

[3] He Huohua, Li Shaohua, Du Jiayuan et al., Prediction of Thin Sand Body Reservoir with Geostatistical Inversion [J], Geophysical and Geochemical Exploration, 2011 35(6): 804-809.

[4] Shang Jianlin, Li Taihui, Huo Xinyong et al., Prediction of Bai 34 Well Site Thin Sand Body in Baikouquan Oilfield with Geostatistical Inversion [J], Xinjiang Petroleum Geology, 2009, 30(6): 758-761.

[5] Liu Zhanzu, Zhang Lei, Ding Qingxiang et aal., Application of Geostatistical Inversion in Identification of Coalbed Methane Thin Reservoir [J], Geophysical Prospecting for Petroleum, 2012, 47(1): 30-35.

[6] Chong Renjie, Liu Jing, Application of Seismic Inversion Data-based Phase Control Reservoir Modeling in BZ25 1 Oilfield [J] China Offshore Oil and Gas (geology) 2003, 7 (5):307- 311.

[7] Yin Yanshu, Zhai Rui, Wu Shenghe, Comprehensive Multi-subject Information Modeling-Take Microfacies 3D Distribution Model of Block 6 in Second Gangdong Development Zone as an Example [J], Natural Gas Earth Science of Journal of Palaeogeography 2007, 18 (3): 408-411.

[8] Zhang Yonggang, Current Status and Development of Seismic Wave Impedance Inversion Technology [J] Geophysical Prospecting for Petroleum [J], 2002, 41 (4): 385-390.

[9] Fang Xiaoyu, Jiang Ping, Ou Zhenneng et al., A New Method to Improve the Reservoir Prediction Accuracy by Combining Geological Modeling and Geological Inversion Technology and Its Application-Take Weizhou 11-1N Oilfield as an Example [J] China Offshore Oil and Gas2012 24 (2): 23-26.

[10] Hu Yong, Chen Gongyang, Zhou Yanli, Application of Seismic Inversion Data in Phase Control Reservoir Modeling [J], Hydrocarbon Geophysical Technique, 2011, 9 (2): 41 43.

[11] Chen Dianyuan, Application of Radom Seismic Inversion Technology in Radom Geological Modeling of WC 131 Oilfield [J] China Offshore Oil and Gas (geology), 2004, 16(4): 250- 253.

[12] Cheng Lihua, Wu Shenghe, Jia Ailin et al., Radom Modeling of Seismic Restriction Stratum by Comprehending More Information-Take J1S22 Sand Group in Well Zone in Jungar Basin as an Example [J] Marine Geology and Quaternary Geology, 2008, 28 (3): 128-131. 